\title{
ВОПРОСЫ ИМПОРТОЗАМЕЩЕНИЯ ВЫСОКОТЕХНОЛОГИЧНОЙ ПРОДУКЦИИ
}

\author{
Ф.И. Шамхалов, Н.С. Николаенков \\ АО «НПП «Пульсар», 105187, г. Москва, Окружной пр., 27
}

\begin{abstract}
В статье рассматриваются вопросы и проблемы современного состояния импортозамещения в российской экономике. На основе анализа доступных статистических данных и нормативно-правовых актов проводится оценка текущей эффективности политики импортозамещения. Проведённое исследование позволяет определить широкий ряд направлений по совершенствованию институциональных и экономических мер по стимулированию импортозамещения с иелью достижения желаемых показателей.
\end{abstract}

Ключевые слова: российская экономика, импортозамещение, план мероприятий, Фонд развития промышленности, диверсификация, оборонно-промышленный комплекс, гражданская продукция

Сведения об авторах: Шамхалов Фарид Имирасланович, д.э.н., профессор; Николаенков Никита Сергеевич, nikolaenkov_n@pulsarnpp.ru

\section{IMPORT SUBSTITUTION TRENDS IN HIGH-TECH INDUSTRIES OF RUSSIAN ECONOMY}

\author{
F.I. Shamkhalov, N.S. Nikolaenkov \\ S\&P Pulsar JSC, 105187, Moscow, Okruzhnoy pr., 27
}

Authors perform the research of topical problems and issues of import substitution policy pursued by Russian authorities. The analysis of available statistics and legal acts provide the insights on effectiveness of the policy. The research allows authors to reveal prospective ways and measures to stimulate the import substitution process in the Russian economy.

Keywords: Russian economy, import substitution policy, institutional action plan, Industrial Development Fund, diversification, military-industrial complex, defense industry, civil sector of the economy

Authors: Shamkhalov Farid Imiraslanovich, Sc.D. professor; Nikolaenkov Nikita Sergeevich, nikolaenkov_n@pulsarnpp.ru 
Импортозамещение в России - одно из главных направлений экономической политики государства. Государство стремится снизить зависимость отраслей экономики от товаров иностранного производства за счёт развития и совершенствования производств внутри государства. Необходимость импортозамещения продиктована критическим отставанием ряда отраслей промышленности от мирового уровня науки и техники.

Для успешной замены востребованных товаров иностранного производства отечественными российская промышленность нуждается в модернизации. В этих целях проводится стимулирующая политика, направленная на создание отечественных аналогов востребованных товаров, технологическое перевооружение предприятий, создание новых высокопроизводительных рабочих мест.

Расчёты, проведённые на основе официальных данных Федеральной службы государственной статистики об объёмах импорта товаров и доле в этом объёме высокотехнологичных товаров, свидетельствуют о том, что объём импорта сначала снизился на $50 \%$ с 24078 млн долл. в 2013 г. до 12028 млн долл. в 2016 г., а в период 2016-2018 гг. вырос на 47,9 \% - с 12028 млн до 17786 млн долл. Таким образом, в последние годы наметился рост объёма импортных товаров на российском рынке. Следует отметить, что в целом доля высокотехнологичной продукции в импорте возросла с 58,7 \% в 2015 г. до $67,2 \%$ в 2018 г. [1, 2].

На рис. 1 представлена статистика импорта высокотехнологичных товаров по годам.

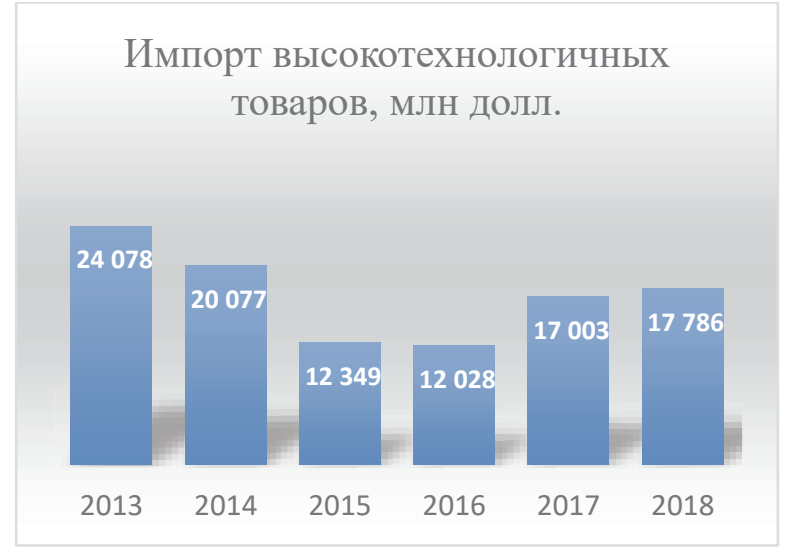

Puc. 1

Импорт высокотехнологичных товаров

Главной причиной возобновления роста импорта в последние годы является технологическое превосходство иностранных производителей над отечественными, что предопределило невозможность замещения широкого спектра высокотехнологичных товаров. Проведённый анализ подтверждает, что даже в условиях усиливающегося санкционного давления и значительного ослабления курса национальной валюты в 2014-2015 гг. объёмы импорта постепенно растут.

Серьёзную обеспокоенность вызывает сохраняющаяся зависимость российского оборонно-промышленного комплекса (далее ОПК) от иностранных поставок комплектующих, обрабатывающего оборудования. Прежде всего это касается современных высокотехнологичных образцов радиоэлектронной техники: именно в этой отрасли технологическое отставание российских производителей в последние десятилетия заметно усилилось.

Особенно остро необходимость интенсивного импортозамещения была осознана руководством страны в 2014 г. из-за значительного удорожания и снижения доступности товаров иностранного производства. 
В принятом Правительством РФ в январе 2015 г. «Плане первоочередных мероприятий по обеспечению устойчивого развития экономики и социальной стабильности в 2015 году» были предусмотрены основные меры по стимулированию импортозамещения, которые можно свести к следующим направлениям:

- ограничение доступа иностранным производителям к участию в закупках, осуществляемых государственными учреждениями и обществами с государственным участием;

- меры по поддержке российского экспорта несырьевых товаров;

- разработка отраслевых программ импортозамещения;

- меры по обеспечению дополнительных заказов для российских производителей транспортных средств, в т.ч. авиатранспорта;

- преобразование Российского фонда технологического развития в Фонд развития промышленности (далее ФРП) с предоставлением возможностей по льготному финансированию проектов в сфере импортозамещения.

В рамках проведения политики стимулирования импортозамещения ФРП предлагает заёмщикам выгодные условия финансирования без использования механизмов государственно-частного партнёрства, т. е. без участия государства в управлении проектом. Главными требованиями являются паритетное софинансирование проекта с заявителем и объём проекта, превышающий 100 млн руб. За 5 лет существования фонда около 290 проектов нашли поддержку со стороны государства через механизм субсидируемого кредита [3].
Следует отметить, однако, явную недостаточность проектов в области микроэлектроники, что препятствует эффективному импортозамещению в этой важной отрасли российской экономики.

В условиях конкуренции российских промышленных компаний как друг с другом, так и с иностранными производителями совершенствование научно-технической базы, разработка новых видов продукции, внедрение инноваций имеют принципиально важное значение. Ввиду того, что ФРП не осуществляет финансирование проектов, направленных на проведение НИОКР, финансирование таких работ осуществляется профильными ведомствами за счёт государственного бюджета.

Одновременно с работой по линии ФРП реализуется масштабная программа НИОКР за счёт средств государственного бюджета. В 2015 г. были инициированы 19 государственных программ в сфере импортозамещения. Такие программы содержат перечни видов продукции, по которым было запланировано интенсивное импортозамещение, с указанием целевых показателей доли импортной продукции на рынке к 2020 г. Впоследствии многие из этих программ были заменены обновлёнными планами в соответствующих отраслях экономики с планами на период 2019-2024 гг.

Сравнение планов импортозамещения на 2015-2020 гг. и на 2019-2024 гг. показывает, что по широкому спектру видов высокотехнологичной продукции за годы их действия зависимость российской экономики от импорта не ослабла, а по некоторым - даже усилилась.

Среди причин низких результатов политики импортозамещения следует отметить 
отсутствие выстроенных технологических цепочек на разных стадиях производства конкретных товаров. Разработка импортозамещающих технологий в отдельных сегментах производственных циклов не позволяет достичь желаемых показателей импортозамещения по конкретным видам товаров.

Программа импортозамещения действует и в отрасли радиоэлектронной промышленности. В рамках этой программы был проведён комплекс НИОКР, направленных на разработку широкого спектра востребованных изделий микроэлектроники и соответствующих технологических производственных процессов. В частности, в области СВЧ электроники основные направления технологического совершенствования предприятий радиоэлектронного кластера обоснованы, например, в трудах видных деятелей отрасли - руководителей $\mathrm{AO}$ «НПП «Пульсар» В.В. Груздова, Ю.В. Колковского, В.М. Миннебаева и др. [4, 5]. Между тем выполнение этих НИОКР не привело к ожидаемому росту производства в отечественной радиоэлектронной отрасли, что было обусловлено следующими причинами:

- технологическим отставанием в связи с устареванием к моменту окончания НИОКР разработанных образцов электронных компонентов в сравнении с актуальными возможностями иностранных производителей;

- технологическими ограничениями в применении новых образцов техники, связанными с недостаточной совместимостью компонентов иностранного и российского производства;

- недостаточным рыночным спросом на новую российскую продукцию электроннокомпонентной базы;
- недостаточной конкурентоспособностью российских производителей высокотехнологичной продукции по издержкам в сравнении с мировыми лидерами.

Спецификой НИОКР, финансируемых из бюджетных источников, является значительный временной разрыв с момента окончания разработки до внедрения для серийного производства. Создание новых изделий с повышенными характеристиками требует проведения соответствующих НИОКР, дополнительных испытаний на более высоких ступенях кооперации с целью их включения в состав производимой продукции. Как показывает многолетний опыт предприятий электронной и радиоэлектронной промышленности, даже простой транзистор может пройти несколько таких ступеней, пока не станет комплектующим готового продукта, поскольку задержка между моментом разработки и началом серийного производства составляет до 7-10 лет.

Также стоит отметить, что действующие государственные программы в сфере импортозамещения не привязаны к конкретным рынкам. Этим определяется невозможность эффективной коммерциализации результатов проводимых НИОКР.

Важным стимулом для интенсификации импортозамещения призвана стать диверсификация производств предприятий ОПК. Плановые показатели диверсификации впервые были представлены в сентябре 2016 г. на совещании по вопросам использования потенциала ОПК в производстве высокотехнологичной продукции гражданского назначения. Планы правительства направлены на доведение доли гражданской продукции предприятий ОПК 
до $30 \%$ общего объёма выручки к 2025 г. и до $50 \%$ - к 2030 г. На заседании военнопромышленной комиссии Президент РФ отметил недостаточную результативность мер по увеличению доли гражданской продукции предприятий ОПК, оценив её в 21 \% в 2018 г. [6].

В условиях снижения объёма государственного оборонного заказа (далее ГОЗ) промышленные предприятия ищут альтернативные способы извлечения прибыли, в том числе путём выявления рыночных ниш в сфере гражданской продукции. Среди реальных мер корпоративного планирования следует отметить централизованное формирование каталогов гражданской продукции предприятий ОПК [7].

Оперативному и эффективному проведению диверсификации производств ОПК препятствуют имеющиеся фундаментальные проблемы, наиболее острыми из которых являются следующие.

Во-первых, закрытость и обособленность ОПК от «гражданского» хозяйственного оборота. Исторически ОПК в России существует и развивается по иным закономерностям, нежели вся остальная экономика. Это касается таких вопросов, как техническое регулирование, стандартизация, выбор материалов и т. д. В этой связи предстоит работа по адаптации существующей производственно-конструкторской базы к нуждам гражданских рынков высокотехнологичной продукции.

Во-вторых, фактическое отсутствие избыточных производственных мощностей, которые могли бы позволить нарастить объёмы выпуска в краткосрочной перспективе [8].
В-третьих, высокий уровень долговой нагрузки, совокупный объём которой у предприятий ОПК оценивается в 2 трлн руб. с ежегодным объёмом расходов на обслуживание долгов в 200 млрд руб. [9] и неизбежно влияет на ограничение возможностей по диверсификации производств, внедрению передовых технологий, кадровому развитию [10]. В последнее время всё чаще высказываются предложения о списании части долгов, однако нерыночные способы разрешения этой проблемы в перспективе могут усугубить негативные последствия кредитной зависимости предприятий.

Кроме того, остро стоит вопрос о преодолении негативной тенденции старения кадров в ОПК. Согласно отчёту Правительства РФ в части выполнения ГОЗ за 20122017 гг. доля работников в возрасте до 35 лет в ОПК возросла с 20 до $30 \%$ [11], чему в первую очередь способствовал рост заработной платы. Для высокотехнологичных производств ОПК требуются дальнейшее омоложение кадрового состава, повышение уровня квалификации.

Решение поставленных задач и преодоление указанных барьеров является необходимым условием для успешной переориентации предприятий ОПК на рынки гражданской продукции и достижения целей политики импортозамещения. В этой связи важно провести анализ успешного опыта российских компаний по осуществлению диверсификационных проектов.

Государственная корпорация «Ростех» - крупнейший российский производитель продукции военного, специального и двойного назначения. В настоящее время 
«Ростех» реализует масштабную программу диверсификации, предполагающую достижение доли гражданской продукции в $50 \%$ уже к 2025 г., чему способствует реализация ключевыми компаниями «Ростеха» широкого спектра проектов для рынков продукции гражданского назначения: например, в авиастроении - магистрального лайнера МC-21, в вертолётостроении вертолёта «Ансат», в медицинском оборудовании, фармакологии и т. д.

Кроме того, «Ростех» активно участвует в масштабных проектах по импортозамещению в партнёрстве с другими крупными компаниями. Например, в рамках Петербургского международного экономического форума в 2019 г. «Ростехом», РЖД и ВЭБ РФ была подписана дорожная карта по импортозамещению цифровой продукции в железнодорожной отрасли. Комплексный системный подход позволит в перспективе обеспечить железнодорожную систему высококачественным безопасным оборудованием российского производства.

Ключевые компании, входящие в государственную корпорацию «Ростех», в стратегическом планировании ориентируются на цели корпорации по диверсификации производств.

Так, АО «Швабе», являющееся ведущим российским производителем оптико-электронных систем военного, специального и двойного назначения, реализует стратегию по диверсификации производства. Среди перспективных проектов АО «Швабе»: строительство Гелиогеофизического комплекса Российской академии наук в 20192023 гг., разработка и промышленное производство импортозамещающих медицинских изделий из углеродных композитных материалов, производство изделий для кардиохирургии, кардиологии и иных областей медицины, развитие направления интеллектуальных транспортных систем [13].

На рис. 2 показано планируемое распределение совокупной выручки АО «Швабе» к 2025 г. по видам продукции.

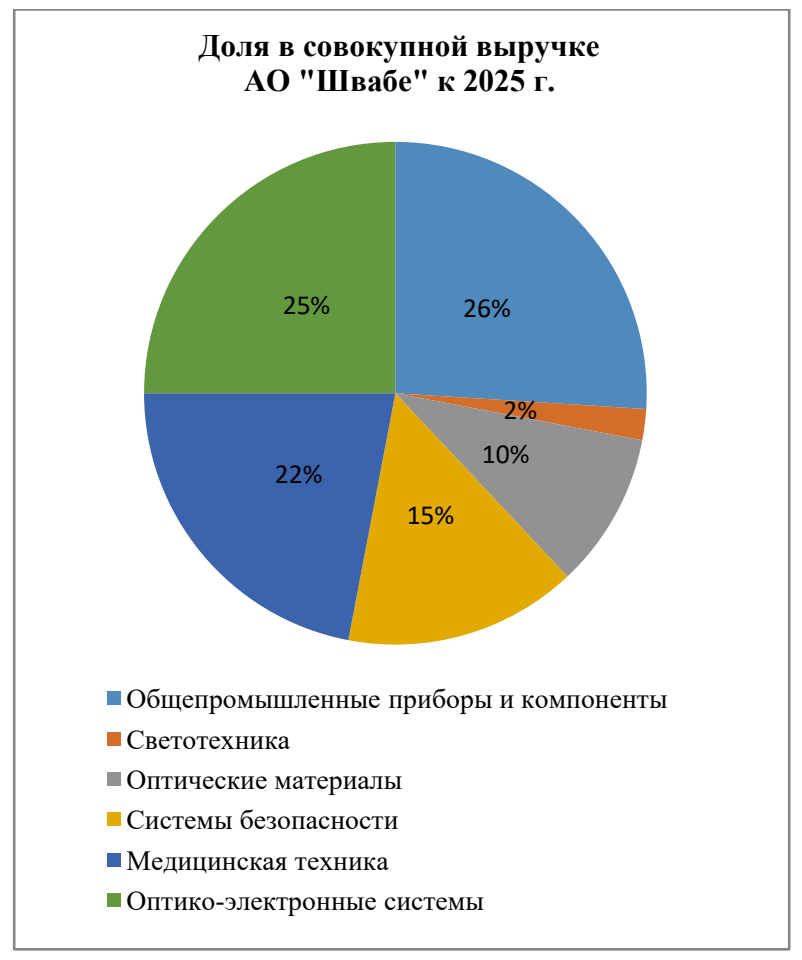

Puc. 2

Распределение совокупной выручки AO «Швабе» [12]

Диаграмма свидетельствует о наличии в стратегии диверсификации «Швабе» трёх ключевых направлений производства «оптические электронные системы», «общепромышленные приборы и компоненты», «медицинская техника». Таким образом, стратегическая цель концерна «Швабе», состоящая в доведении доли гражданской продукции в выручке до 81 \% к 2025 г. [12], превышает запланированный корпорацией «Ростех» уровень в $50 \%$. 
Концерн «Калашников», акционером которого является «Ростех», после реформирования в 2013 г. провёл ребрендинг и в 2016 г. в значительной степени обновил основные фонды. Достижение 50 \%-й доли гражданской продукции является стратегической целью холдинга на перспективу 5 лет. Концерн развивает такие направления гражданских производств, как стрелковое оружие гражданского назначения, беспилотные летательные аппараты, гражданское судостроение, а в перспективе перейдет к освоению новых продуктовых сегментов робототехники, мототехники, продуктов на базе нейросетей [13].

В радиоэлектронной отрасли $\mathrm{AO}$ «Росэлектроника» реализуется широкий круг проектов в целях импортозамещения. Среди них следует отметить такие ключевые проекты, как цифровизация электрических сетей для нужд ПАО «Россети», развитие инспекционно-досмотровых комплексов, проекты «Умный город», «Умная медицина» [13].

Важную роль в процессе диверсификации играет широкое участие «Ростеха» в реализации масштабной программы национальных проектов. Корпорация участвует во всех запланированных программах, а для проекта «Цифровая экономика» является ключевым центром компетенции по направлениям нейротехнологий, искусственного интеллекта, систем распределённого реестра, промышленного интернета, робототехники, сенсорики и беспроводной связи.

Таким образом, импортозамещение остаётся важным направлением в российской экономике, определяющим развитие высо- котехнологичных производств. К настоящему моменту отработаны и эффективно действуют различные меры государственной поддержки импортозамещения. Задачи по диверсификации предприятий ОПК и выполнению ключевых национальных проектов в областях цифровой экономики, здравоохранения, экологии, стимулирования экспорта высокотехнологичной продукции согласуются со стоящими в рамках политики импортозамещения задачами.

Анализ происходящих в российской экономике процессов, связанных с импортозамещением, позволяет сформулировать следующие выводы.

1. Необходимость экономической детерминированности мер поддержки импортозамещения реализуется в механизме государственного софинансирования проектов через Фонд развития промышленности. Требование экономической обоснованности каждого проекта, претендующего на государственную поддержку, является ключевым для успешности всей программы в целом.

2. В решении задач импортозамещения следует сделать акцент на проведении политики в отношении конкретных рынков товаров, а не отдельных видов продукции. Возможным решением могут стать определение ключевых для импортозамещения рынков с оценкой потенциального спроса в экономике, применение комплексного стратегического подхода к оценке, планированию, осуществлению проектов в сфере импортозамещения.

3. В целях обеспечения гармонии и синергии от проведения прикладных и фундаментальных НИОКР в различных областях 
науки и техники и достижения стратегических целей таких работ целесообразно решение вопроса о создании независимого органа, координирующего государственные программы, направленные на технологическое развитие. Координация и экономический анализ проектов технологического прорыва в перспективе позволят сократить существующее отставание российских производств от мирового уровня. Необходимо подчеркнуть, что к координационной функции относится проведение или планирование предпроектных изысканий, направленных на изучение технического уровня в исследуемой области, потребностей рынка, препятствий к реализации проектов различного характера.

4. Важным представляется обеспечение увязки политики импортозамещения с объективно протекающими процессами диверсификации производств компаний ОПК. Меры государственной поддержки предприятий в этой сфере могут быть высокоэффективными в таких областях, как развитие человеческого капитала, критических технологий, а также достижение основных целей национальных проектов и программ.

5. Представляется необходимой разработка на государственном уровне рыночных механизмов, способствующих снижению долговой нагрузки предприятий ОПК.

6. Расширение перечней мер и способов государственной поддержки импортозамещения должно сопровождаться соответствующим повышением уровня государственного финансового контроля за эффективностью расходования средств федерального бюджета, в частности посредством систем ключевых показателей эффективности для руководства государствен- ных органов, учреждений, компаний и сотрудников.

7. В целях достижения высокого уровня качества товаров российского производства необходимо проведение соответствующей политики в области стандартизации производств, обеспечение контроля качества производств.

\section{Литература}

1. Импорт товаров (по данным таможенной статистики) // Федеральная служба государственной статистики: [официальный сайт]. URL:https://fedstat.ru/indicator/37148

2. Доля высокотехнологичных товаров в общем объёме импорта // Федеральная служба государственной статистики: [официальный сайт]. URL: https://fedstat.ru/indicator/50206

3. Фонд развития промышленности: [официальный сайт]. URL: https://frprf.ru/proekty-i-zayavki/proekty/

4. Васильев, А.Г. SiGe и $\mathrm{GaN}$ CВЧ приборы для приёмопередающих модулей / А.Г. Васильев, Ю.В. Колковский, С.В. Корнеев, А.А. Дорофеев, В.М. Миннебаев // Электронная техника. Серия 2. Полупроводниковые приборы. 2009. - № 2 (223). - C. 5-10.

5. Груздов, В.В. СВЧ электроника на нитриде галлия - основное направление создания радиоэлектронных систем / В.В. Груздов Ю.В. Колковский, В.М. Миннебаев // Электронная техника. Серия 2. Полупроводниковые приборы. - 2013. - № 2 (231). - С. 88-101.

6. Заседание военно-промышленной комиссии: [сетевая публикация]. Ижевск, 2019. URL: https://rg.ru/2019/09/19/reg-pfo/vladimir-putinprizval-uskorit-diversifikaciiu-opk.html

7. Материалы конференции по диверсификации // Международная выставка Interpolitex: [официальный сайт]. 2019. URL: https://www.interpolitex.ru/ media/news/novosti-bezopasnosti/dmitriy-rogozin na-konferentsii-po-diversifikatsii-v-permi-rassk zal-o-prioritetakh-opk/

8. Диверсификация ОПК: цель, промежуточный этап или средство развития? // Новый оборонный заказ: 2019. №4 (57). URL: https://dfnc.ru/oboronzakaz/diversifikatsiya-opktsel-promezhutochnyj-etap-ili-sredstvo-razvitiya/ 
9. Почему российскому ОПК потребовалось списание Р700 млрд кредитов // РБК: сетевая публикация. - 2019. URL: https://www.rbc.ru/economics/08/07/2019/5d2320289a7947771c7d26ea? fromtg $=1$

10. Совещание по финансовому оздоровлению организаций ОПК // Президент России: сетевая публикация. - 2019. URL: http://kremlin.ru/ events/president/news/61839.

11. Оборонно-промышленный комплекс. Государственный оборонный заказ: некоторые факты за 6 лет // Правительство Российской Федерации: сетевая публикация. - 2018. URL: http://government.ru/info/32164/

12. Швабе: [официальный сайт]. Стратегия развития 2020. URL: https://shvabe.com/about/disclosure/.

13. Государственная корпорация «Ростех»: [официальный сайт]. Годовой отчёт за 2018 г. URL: https://rostec.ru/upload/iblock/587/587257de2477 09537226335c9b40b76a.pdf

\section{References}

1. Import of goods (according to customs statistics). Federal State Statistics Service of the Russian Federation, available at: URL: https://fedstat.ru/ indicator $/ 37148$

2. The share of high-tech products in the total import. Federal State Statistics Service of the Russian Federation, available at: URL:https://fedstat.ru/indicator/50206

3. Industrial Development Fund, available at: URL:https://frprf.ru/proekty-i-zayavki/proekty/

4. Vasilyev A.G., Kolkovskiy Yu.V., Korneev S.V., Dorofeev A.A., Minnebaev V.M. SiGe i GaN SVCH pribory dlya priyomoperedayushchikh moduley [SiGe and GaN microwave devices for transceiver modules]. Electronic engineering. Series 2. Semiconductor devices, 2009, no. 2(223), pp. 5-10.

5. Gruzdov V.V., Kolkovskiy Yu.V., Minnebaev V.M. SVCH elektronika na nitride galliya - osnovnoye napravleniye sozdaniya radioelektronnykh sistem [GaN microwave electronics the main direction of electronic system creation]. Electronic engineering. Series 2. Semiconductor devices, 2013, no. 2(231), pp. 88-101.
6. Proceedings of the Military Industrial Commission Meeting, Izhevsk, 2019, available at: URL:https://rg.ru/2019/09/19/reg-pfo/vladimirputin-prizval-uskorit-diversifikaciiu-opk.html

7. Materialy konferentsii po diversifikatsii [Proceedings of the Conference on diversification]. Interpolitex-2019, available at: URL: https://www.interpolitex.ru/media/news/novosti-bezopasnosti/ dmitriy-rogozin-na-konferentsii-po-diversifikatsiiv-permi-rasskazal-o-prioritetakh-opk/

8. Diversifikatsiya OPK: tsel', promezhutochnyy etap ili sredstvo razvitiya? [Diversification of the defense industry: final objective, intermediate stage or means of development?]. Noviy oboronniy zakaz, 2019, no. 4(57), available at: URL:https://dfnc.ru/oboronzakaz/diversifikatsiya -opk-tsel-promezhutochnyj-etap-ili-sredstvorazvitiya/

9. Pochemu rossiyskomu OPK potrebovalos' spisaniye P700 mlrd kreditov [Why does the Russian defense industry wants to write off P700 billion of loans]. 2019, RBC, available at: URL: https://www.rbc.ru/economics/08/07/2019/5d232 0289a7947771c7d26ea?fromtg=1

10. Soveshchaniye po finansovomu ozdorovleniyu organizatsiy OPK [Proceedings of the meeting on the financial recovery of defense industry organizations]. 2019, official website of the President of Russia, available at: URL: http://kremlin.ru/events/president/news/61839

11. Oboronno-promyshlennyi kompleks. Gosudarstvennyi oboronnyi zakaz: nekotoryie fakty za 6 let [The military-industrial complex. Government's defense order: some facts for 6 years]. 2018, official website of the Russian Government, available at: URL: http://government.ru/info/ 32164/

12. Strategiya razvitiya Shvabe do 2020 goda [The development strategy of Shvabe until 2020] Shvabe Holding, available at: URL: https://shvabe.com/about/disclosure/

13. Godovoy otchet za 2018 god korporatsii Rostekh [Rostec annual report for 2018], State Corporation Rostec, available at: URL: https://rostec.ru/ upload/iblock/587/587257de247709537226335c9b 40b76a.pdf 